\title{
Lean and energy efficient production based on internet of things (IOT) in aviation industry
}

\author{
Aleksandr Korchagin ${ }^{1,2}$, Antonina Deniskina ${ }^{1}$ and Irina Fateeva ${ }^{3, *}$ \\ ${ }^{1}$ Moscow Aviation Institute, Volokolamskoe highway, 4, Moscow, 125993, Russia \\ ${ }^{2}$ School of Aeronautics and Astronautics, Shanghai Jiao Tong University, Shanghai, China \\ ${ }^{3}$ Voronezh State Technical University, Moscow Avenue, 14, Voronezh, 394026, Russia
}

\begin{abstract}
Nowadays, the interest to lean manufacturing increases every year and a lot of aviation companies use it on their practice. At the same time, Internet technologies also entered in the production of modern aircrafts. For increasing quality and safety of aviation products, in this article it was suggested to use lean manufacturing and Internet of Things technologies for Russian and Chinese aircraft production systems. There is a successful case study of Boeing company, which achieves great results due to these technologies. For realizing this idea on the practice, at first, it is needed to model and analyze the implementation of this technologies on production system and understand is it profitable or not. In this paper, it was proposed to use Discrete Event Simulation method, which proves its imitation on the real practice and possibility of its realization. The results show that we can easily use ARENA software (which is based on DES modelling) for proving the efficiency of Lean and IoT technologies. In conclusion, it becomes obvious that due to the rapid development of Internet technologies it is necessary to integrate it with the lean manufacturing process and analyze its implementation.
\end{abstract}

\section{Introduction}

The concept of lean manufacturing, which was developed in 1950-s by Toyota company, increases the efficiency of production in different industries. Nowadays, it is used not only in automobile industry, but also in healthcare, ship production and aircraft industry as well. This technology had a successful effect on production system of companies, but science and technology progress doesn't stand still. Internet technologies and Artificial Intelligence transforms the traditional model of production system and we entered in the new era of digital data and processes. Thus, it becomes obvious that it is needed to modify Lean production system and adopt it to the new Internet of Things technologies.

In other authors publications [1-3] the idea of integration Lean Manufacturing with Internet of Things has been already suggested. In [1] it was told about Lean Six Sigma Approach with IoT for logistics system. In [2] it was suggested to integrate Lean with Supply Chain Management and Internet of Things. Authors of [3] considered the global

\footnotetext{
${ }^{*}$ Corresponding author: belyaeva-sv@mail.ru
} 
integration model of Lean and Industry 4.0. approaches. They build a new cyber-physical model of Just-in-Time delivery.

However, there are no publications about the implementation of this idea for aviation industry and its efficiency and profitability.

In this paper, it will be considered the Boeing's successful implementation of these technologies and possibilities of its deployment to the Russian United Aircraft Corporation (UAC) or Commercial Aircraft Corporation of China (COMAC). For proving the efficiency of technologies, it will be used simulation research methods.

\section{Literature review}

\subsection{Lean Manufacturing for aircraft production}

Nowadays, in the aircraft industry there is a struggle to improve the quality of products. More efficient management methods are being introduced in this sector, production technology is changing, and external economic relations are being reorganized. Ensuring the competitiveness of the aviation enterprises requires building both a more rational structure and an increase in its technological level. Thus, the modern aviation company will have to apply the latest methods of effective management and optimize the use of all resources types.

Currently, the following main approaches are used to improve the efficiency of enterprises [4]:

- Lean production

- The concept of Six-Sigma

- Total production optimization

- The system of 20 "keys"

- The theory of constraints

A special place in the combination of instruments for minimizing production costs and increasing the efficiency takes the concept of lean production [5].

The term of lean production was firstly appeared in the book "The Machine that Changed the World", where the authors described Toyota Production System, which was based on this technology [6]. Application of this approach allowed Japanese enterprises to provide production with high quality and with rather low-cost value [4].

The efficiency of lean process is based on the avoiding unnecessary activities, which haven't a significant effect on the production process of the enterprise. The disposal of waste operation helps to save money for production and optimize the product cost and resources on its making. Saving only useful operations, which are required for the production, is a successful instrument for achieving the goals and satisfying customer needs and requirements [7].

There are seven types of wastes during the product manufacturing, which were suggested by Taiichi Ohno, the creator of lean technology in Toyota Motors Company:

- wastes due to overproduction - manufacturing of products that are not in demand or in a larger volume earlier than it is required at the next stage of the process

- time waste due to waiting - breaks, associated with waiting for people, materials, equipment or information

- wastes due to excessive processing - additional processing of the product due to the tool's poor quality, design mistakes and etc.

- wastes due to unnecessary movements during operations - any movement of people, tools or equipment that does not add value to the final product 
- wastes due to inventory - any excessive inflow of products (raw materials or finished product) in the production process

- wastes during transportation - unnecessary movement or long-distance movement of materials, parts, products

- wastes due to the release of defective products - products that require inspection, sorting, recycling, replacement or improvement [4].

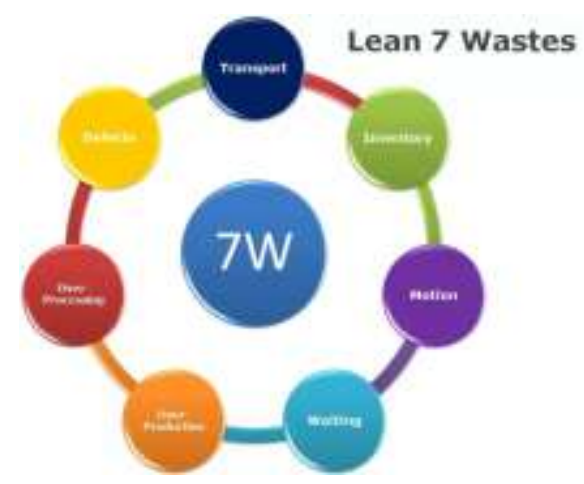

Fig. 1. 7 Wastes, according to Lean Technology [8].

Lean manufacturing consists of different methods, tools and techniques, which are aimed on the loss reduction or elimination during the production process:

- Cellular manufacturing: Organizes the entire process for a particular product or similar products into a group (or "cell"), including all the necessary machines, equipment and operators. Resources within cells are arranged to easily facilitate all operations.

- Just-in-time (JIT): A system, where a customer initiates demand, and the demand is then transmitted backward from the final assembly all the way to raw material, thus "pulling" all requirements just when they are required.

- Kanbans: A signaling system for implementing JIT production.

- Total preventive maintenance (TPM): Workers carry out regular equipment maintenance to detect any anomalies. The focus is changed from fixing breakdowns to preventing them. Since operators are the closest to the machines, they are included in maintenance and monitoring activities in order to prevent and provide warning situations.

- Setup time reduction: Continuously try to reduce the setup time on a machine.

- Total quality management (TQM): A system of continuous improvement employing participative management that is centered on the needs of customers. Key components are employee involvement and training, problem-solving teams, etc. [9]

According to [4], by using these methods and tools the enterprise can achieve the following results:

- reducing the cost of production by $50 \%$;

- decrease the duration of the production cycle by $50 \%$;

- reducing labor costs by $50 \%$ while maintaining or improving productivity;

- increase production capacity by $50 \%$ at the same areas;

- reduce inventory by $80 \%$;

- improve product quality;

- increase profits;

- create a flexible production system that allows you to quickly respond to changing consumer demands.

Due to the large number of advantages of lean production, this technology has been applied in trade, service segment, health care, the armed forces and the public sector. Using 
the experience of Toyota, developed industrial countries began to create their production systems. In the United States, lean manufacturing techniques are used in the automobile industry, in aviation (Boeing - BPS production system) and other fields.

\subsection{Internet of Things and its technologies}

The idea of creating Internet of Things belongs to British businessman, Kevin Ashton in 1999. He defined it as communication system of devices with sensors via a computer network [10].

In other words, Internet of things (loT) is a large-scale data flow environment, which is supported by deploying global smart objects that continuously collect huge amounts of data [11].

The Internet of things is based on three basic principles. Firstly, the widespread communication infrastructure, secondly, the global identification of each object and, thirdly, the ability of each object to send and receive data through a personal network or the Internet to which it is connected.

The most important differences between the Internet of things and the existing Internet of people are:

- focus on things, not on people;

- significantly greater number of connected objects;

- significantly smaller size of objects and low speed of data transmission;

- focus on reading information, not on communications;

- the need for new infrastructure and alternative standards [12].

According to [12] and [13], Internet of Things architecture consists of 3 main levels: perceptual, network and application levels.

- Perceptual or sensor level: The lowest level of IoT architecture consists of "smart" objects integrated with sensors (sensors). Sensors realize the connection of physical and virtual (digital) worlds, providing the collection and processing of information in real time. There are different types of sensors for appropriate purposes, such as temperature, pressure, speed, location, etc.

- Network level: The large amount of data generated at the first IOT level by numerous miniature sensors requires a robust and high-performance wired or wireless network infrastructure as a transportation environment. To implement a wide range of services and applications in IoT, it is necessary to ensure that multiple networks of different technologies and access protocols work together in a heterogeneous configuration. This layer consists of convergent network infrastructure, which is created by integrating networks into a single network platform.

- Application level: At the third level of IOT architecture, there are different types of applications for the relevant industrial sectors and fields of activity (energy, transport, trade, medicine, education, etc.). Applications can be "vertical" when they are specific to a particular industry, as well as "horizontal" applications (e.g. fleet management, asset tracking, etc.) that can be used in different sectors of the economy [12].

Through IoT technologies, manufacturing companies will be able to optimize everything from the warehouse to the execution of production tasks directly, if each industrial building, vehicle and even tool will be equipped with sensors and will regularly send a report on their condition, location and other characteristics. Let's consider the manufacturing technologies of Internet of Things in a more detailed way. There are seven technologies, which are implemented in production system:

1. Coding technology - Electronic Product Code (EPC) is mainly used to store the enterprise code, commodity code and serial number, etc.; this unique identification means that a single item corresponds to the codes. Thus, coding effectively achieves the 
digitization of goods; it can thus provide global product tracking and a tracking trace, so effectively improving the level of supply chain management and reducing logistics costs.

2. Electronic Tags - An electronic tag consists of a coupling element and a chip; each tag has a unique electronic code attached to the surface of the target object. The electronic tag stores specified information about the object, this information can be automatically loaded into the system by means of wireless data communication.

3. RFID Technology - This is a wireless communication technology that utilizes radio frequencies to enable contactless information transmission through space and hence achieve identification. Its system structure consists mainly of a host system, reader and electronic label.

4. GIS/GPS Technology Geographic Information System (GIS) is composed of computer hardware and software and a geospatial database. It is based on the theory of system engineering and information science and helps analyze the spatial data for management and decision-making. Global Positioning System (GPS) refers to a satellite positioning system that uses navigation satellites for time measurement and ranging on a global scale to achieve user positioning and navigation.

5. Wireless Sensor Network Technology Wireless Sensor Network (WSN) is a wireless network composed of a large number of static or dynamically distributed sensors. It is composed of task management nodes, sink nodes and a large number of sensors scattered in the monitoring area.

6. Network Communication Technology - The Internet of Things networking technology is divided into two categories: wide area network communication technology and shortrange communication technology. Wide area network communication technology consists (mainly) of the Internet, mobile network and satellite communication technology. The short distance communication technology includes Bluetooth, ZigBee, Wireless-Fidelity (Wi-Fi), Near Field Communication (NFC) and Ultra-Wideband (UWB).

7. Cloud Computing Cloud Computing is a computing resource that is dynamic, scalable and virtualized, based on the growth, usage and delivery patterns of Internet-related services. The IOT requires a lot of computing resources, with the load changing rapidly; as a service, cloud computing should provide adequate computing resources for the application of the IOT in the future [13].

\subsection{Integration of Lean Manufacturing and Internet of Things}

For decreasing wastes in the manufacturing system and realizing Lean Manufacturing in the aircraft enterprise, the use of Internet technologies helps to achieve the defined goals. Information networks with reliable databases, which connect all production processes and activities in the whole system, becomes more and more reliable with the technology development. The use of Internet of Things technology in Lean Production System has a lot of advantages for organizing the aircraft manufacturing [14].

Implementation of this technology is especially important in aviation industry. Since the requirements to the quality and safety of aircrafts are growing steadily, manufacturers are interested in the possibilities to control the operation of the main systems and parts of already released and sold airplane. In other words, the aviation plant wants to stay in contact with them, and it is possible due to the worldwide network. In the future, any airplane will become part of the Internet of things. The aircraft will be able to communicate with its manufacturer and, for example, to inform him that it needs early maintenance. Sensors online will notify, for example, about overheating, vibration, premature wear of a particular node or unusual sounds.

Such an intelligent digital system will continue to install on all machines and tools. Each node of the machine or equipment will perform self-diagnostics and report its status 
via the Internet to the appropriate operational control center. Such solutions will have several advantages for the producers themselves. Thus, companies will be able to plan the production more efficiently and supply of spare parts, they will be able to track how often these nodes face certain problems and in a timely manner to make the necessary engineering changes. In addition, they will be able to inform the client about the need to replace a node.

With using Internet of Things, it will be possible the unification of all measuring and control devices and sensors of production system into a single information network. Reducing production costs, efficient energy consumption, abandoning economically unprofitable assets - all this together will significantly reduce the cost of production [12].

\section{Case study: boeing company}

\subsection{Lean implementation}

Implementation of lean production system in Boeing began in the early 90 -es. At that time, there was an urgent need to increase the pace of production, while the ability to expand production areas was not. There was also a deficit of skilled personnel. Therefore, Boeing turned to the experience of Toyota, which at that time was the leader in the automotive industry and recognized champion in the implementation of lean manufacturing system.

For training of highly qualified personnel, who would know the fundamental principles of lean technology, the best Toyota coaches were invited. They were in the shops every day and passed on the experience to American engineers - taught to think and act differently. The process of transition to the new system took about ten years.

After staff training and realizing lean production system on the practice the foundation of Boeing's growth was laid and the performance indicators started to go up. It was happened due to the implementation of the following tools:

- Value Stream Mapping.

In the easiest way, it is a process of identifying and eliminating all sorts of losses in complex and time-consuming operations. It is rather difficult task because every activity is analyzed to the smallest details.

- There are also tools that connect several processes to each other - for example, the Boeing company uses the tool LDBR (Lean+ Design Build Roadmap). This is the link between those who design the product and those who subsequently manufacture and assemble it. For the successful collaboration of designers and mechanics this tool was invented. In total, there are just over ten such instruments in the Lean system [15].

In general, Boeing's Lean+ toolkit is a comprehensive collection of tools that support "kaizen" (continuous improvement) activities. The toolkit also contains useful resources that support the discovery, reduction, and elimination of hidden waste that exists in Boeing processes [16].

Now the company produces 42 Boeing 737 aircraft a month - it is four times more than 15 years ago. At the same time, production areas decreased three times, and the number of employees remained the same. The company managed for the first time in the history of civil aviation to put the Assembly of aircraft on a moving conveyor. The number of parts, components and assemblies in a single plane is of the order of 7-8 million items. In fact, two planes are rolled out of the workshop gates every day. All this became possible thanks to the introduction of lean production system [15].

From the speech of the head of Boeing Commercial Airplanes Ray Conner at the Paris Air Show in Le Bourget: "over the past five years, we have increased the rate of production 
of aircraft by more than $60 \%$ through the use of lean manufacturing system and responsible approach to the creation of our products."

When assembling the 737 aircraft, the time was reduced by $50 \%$. The turnover of warehouse stocks increased by $132 \%$, and the cost of quality assurance decreased by $55 \%$. $41 \%$ reduction in the production area. All this for 5 years.

When assembling 777 , the time was reduced by $14 \%$, the turnover of warehouse stocks increased by $32 \%$, the quality of engineering work on all parts of the aircraft structures increased by $30 \%$, the cost of quality assurance decreased by $10 \%$, production areas decreased by $43 \%$ [17].

\subsection{Internet of Things Implementation}

Using Internet of Things Technology, Boeing modernize its supply chains, operational platforms and factories.

Boeing used the following principles during implementation of Internet of Things in their company:

- Work experience with intelligent equipment - connecting people and data in the whole network helps to simplify and broaden the human knowledge and to get customer satisfaction

- Smarter Machines - It is needed to improve M2M communication and predictive analytics for providing new type of machine workers.

- Security provision - the information should be protected, and the privacy should be saved

- Flexible infrastructure - empowerment of people to use data-driven analytics with a flexible and transparent infrastructure.

- Enhanced harmony - balance innovation ideas, business processes, new methodologies impact.

- Implementing Internet of Things, Boeing company achieves significant results:

- transformation their aerospace business model, due to the appearance of smart factories, new customer types and increasing their revenue streams

- integration of information and operational technologies: the whole fabric system, which connects a lot of processes, machines and people [18].

In the near future, Boeing would like to combine Internet of Things with blockchain technology.

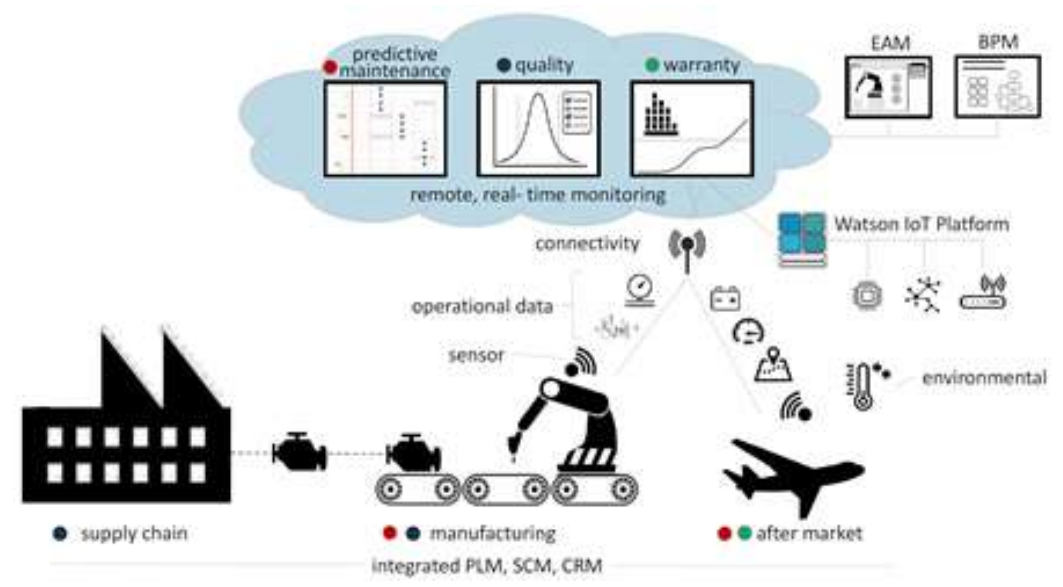

Fig. 2. Implementation of IoT in Boeing's manufacturing [19]. 
One such use is the production, in particular, to track and maintain the life cycle of parts, where the blockchain managed by IoT can be used to track the origin of individual parts from the date of manufacture to complete removal.

Thus, Internet of Things with blockchain will give Boeing the following results [19]:

- Maintenance processes prediction

- Optimizing manufacturing processes

- Increase of components life cycle

\section{Simulation methods}

In this paper, we propose to use modeling methods to prove the effectiveness of lean manufacturing technologies and "Internet of things" and to determine its feasibility in practice.

Simulation methods are the tools, which can be used for system design and improvement, implementation of new technologies and its imitation on the real manufacturing foundation [20]. Thus, it helps to understand how the new techniques and tools can be realized in the real practice. Building an objective and precise simulation model can help the company to analyze the system and avoid mistakes in the future. Simulation can be defined by Banks [21] as "imitation of the operation of a real-world process or system over time".

Nowadays, there are described a lot of simulation methods, which can be used for process improvement analysis. The most common simulation tools, which are considered in the articles, are the following [22]:

- Linear Programming

- Markov Chain Analysis

- Discrete-Event Simulation (DES)

- System Dynamics

- Monte-Carlo Simulation

- Value Stream Mapping

There are two methods, which are used for Lean and IoT implementation by most of authors [23-32] - Value Stream Mapping and Discrete-Event Simulation. Let's analyze these two methods and determine which one is more suitable for our case.

In Lean Manufacturing, Value Stream Mapping is one of the main methods for data and products flows interpretation in the production system, which considers a lot of assets: from raw materials to finished products. This type of analysis starts from building Current State Map, which gives us the current processes system of processes and materials. Then, we should to draw Future State Map and to define the improvements for our production system [23].

In [24] this analysis helped to understand the impact of Kanban methodology on the footwear manufacturer enterprise. In the result, the new production system obtained less inventory and unnecessary activities, which leaded to the production lead time decrease.

Value Stream Mapping simulation method has the following advantages and disadvantages [25]:

Table 1. The advantages and disadvantages of Value Stream Mapping.

\begin{tabular}{|c|c|}
\hline \multicolumn{2}{|l|}{ Value Stream Mapping } \\
\hline Advantages & Disadvantages \\
\hline Can be easily and fast performed & pe of product can be \\
\hline $\begin{array}{l}\text { Cheap method, there is no need to have a lot of } \\
\text { equipment and staff } \\
\text { Simple to learn and understand }\end{array}$ & $\begin{array}{l}\text { This method provides only the production } \\
\text { processes at certain moment of time }\end{array}$ \\
\hline
\end{tabular}


Only pen and paper needed for it

Can be a good foundation for another methods

Can be made by staff, who knows the production system well, with VSM specialist's

support

Comparing with Value Stream Mapping, Discrete Event Simulation is more comprehensive and powerful tool and can represent inner processes and activities in the system in a more detailed way and satisfy the initial goals of the analysis [26].

The idea of DES is based on the principle of triggers simulation, which represents the statistical distribution. Each trigger can help to generate discrete events, which can be analyzed during all period of production time. For Discrete Event Simulation time is crucial factor, because this type of simulation is dynamic, and the outputs depends on the time [27].

Discrete Event Simulation also has a lot of advantages and disadvantages, according to [26] and [27]:

Table 2. The advantages and disadvantages of Descrete Event Simulation.

\begin{tabular}{|c|c|}
\hline \multicolumn{2}{|l|}{ Discrete Event Simulation } \\
\hline Advantages & Disadvantages \\
\hline $\begin{array}{l}\text { Can be easily change the conditions and } \\
\text { experiment with the system } \\
\text { Fast method, because for model } \\
\text { reconstruction there is no need extra time } \\
\text { Decision-making based on this method is } \\
\text { easy, quick and precise } \\
\text { Gives deeper system analysis and } \\
\text { understanding } \\
\text { Dynamic nature of method, thus time is taken } \\
\text { into consider } \\
\text { Can be used both for problem identification } \\
\text { and its solving } \\
\text { One of the best methods for complex systems }\end{array}$ & $\begin{array}{l}\text { It is needed to spend a lot of time and people } \\
\text { for this method analysis } \\
\text { Wrong initial model can give the precise } \\
\text { results, so it is difficult to diagnose the } \\
\text { problems } \\
\text { This method is suitable for machines processes } \\
\text { simulation, but not for people simulation } \\
\text { DES is more difficult to implement by } \\
\text { enterprises }\end{array}$ \\
\hline
\end{tabular}

As Discrete Event Simulation was made for comprehensive analysis of complex systems, which have a network of production processes and materials, the system can be simulated through various software, that can significantly reduce the time of analysis and necessary staff for its performance.

Due to the fact that the aviation production system is an extremely complex network of processes and materials that requires a detailed approach to the analysis of the implemented technologies, we can conclude that the method of DES modelling is the most preferable for our research.

\section{Arena software and its advantages}

There are a lot of software, which are used by a lot authors for DES: AutoMod [26], ABB [27], Simul8 [28], ARENA [29,33], ProModel [30], FactsAnalyzer [31]. In [32] the simulation program for aircraft supply chain Global Hawk was built and tested for identifying improvements after lean implementation.

ARENA software is used in most cases for Lean Discrete Event Simulation and it has a lot of benefits for its performance:

- This computer program is perfectly suitable for large-scale and complex production system, because it can simulate the global processes network fast and easily 
- It gives a huge amount of reports, which helps to analyze different production output parameters, such as lead time, work-in-process, inventory number, resource and staff utilization.

- The performance indicators are determined and evaluated using appropriate statistical functions [33].

ARENA, developed by Systems Modeling Corporation software for simulation modeling, allows you to create mobile computer models, using which you can adequately represent a lot of real systems. The first version of this system was released in 1993. Arena is equipped with a convenient object-oriented interface and has amazing opportunities to adapt to all kinds of subject areas. In general, the system is extremely easy to use.

The foundation of ARENA software is the SIMAN simulation language and the Cinema Animation system. SIMAN, first implemented in 1982, is an extremely flexible and expressive modeling language. It is constantly being improved by adding new features. To display the simulation results used animation Cinema animation system, known on the market since 1984, the modeling process is organized as follows. First, the user step by step builds a model in the visual editor of the Arena system. Then the system generates the corresponding code on the SIMAN, and then automatically starts Cinema animation.

New policies, management procedures, decision rules, organizational structure, information flows, etc. can be investigated without interfering with the operation of the real system. New hardware, hosting plans, software, transportation systems, etc. can be tested before money, time and other resources are spent on their acquisition and/or creation. Simulation modeling allows us to test hypotheses about the causes of certain observed phenomena. SIMAN allows you to view processes at different time scales. SIMAN allows you to identify the variables that are most important for the successful operation of the simulated system, and to analyze the connections between them. SIMAN allows you to identify bottlenecks in material, information and other flows. Simulation gives the opportunity to explore the objects, about the behavior which you have insufficient information. One of the main advantages of simulation is that it helps to answer the question "what if..."[34].

When the fate of the enterprise is at stake, Arena helps to choose the most profitable strategies and gives confidence when starting up, while allowing you to eliminate unnecessary costs, optimize investments and strengthen relationships with customers.

Arena has allowed organizations in different countries

- to avoid costly mistakes caused by the implementation of extremely intuitive solutions;

- to develop processes to deal with deadlocks and uncertainty caused by randomness and volatility of systems;

- to detect hidden reserves and eliminate inhibiting factors in existing implementations and internal processes;

- to strengthen relations with customers by improving the quality of services and the speed of their provision [35].

Arena includes templates solutions (Application Solution Templates) [36]. Each such template is a set of specialized modules that turn Arena into a problem-oriented modeling environment. By creating such templates or modifying existing ones, you can fully adapt Arena to solve the problems you face and move from abstract concepts of modeling methodology to the terms accepted in the subject area.

The Arena template is the main collection of more than 60 modules provided within the overall Arena system. It was designed to provide a set of general-purpose modeling features for all types of applications. In addition to providing basic functions for resources, queue, inspection, system logic and external file interface, the Arena template provides modules specifically focused on specific aspects of material production and processing. 
For manufacturing, it contains modules that include such features as machine downtime and maintenance schedules. For material handling applications, modules exist for representing conveyors (synchronous and asynchronous) and various types of transportation devices.

Three panels compose the Arena template:

1) the common panel, containing modules representing the main processes of simulation, such as the arrival, service and departure;

2) a backing panel that contains additional modules for specific actions and the decision-making logic;

3) a transfer panel whose modules are used to model the transfer (or flow) of objects through the system.

In order to develop a simulation model using the Arena template, the user simply selects the module, places it in the model, and then requests the necessary information. For example, when placing a server module from the Arena template, the user is asked for information such as the time of the entities on the server, the server schedule, and where the entities should be sent. After answering with the relevant information, the user closes the dialog to accept the finished module. Animation is automatically enabled with many modules in the Arena template. The graphic symbols that are automatically provided when the module is placed from the Arena template can be modified with built-in Arena graphics tools (similar to CAD systems) or replaced with icons from the Arena symbol library or from external applications [37].

Thus, ARENA is suitable for our research because of its wide sets of tools and its ease of use. By this software, we will be able to build a production model for aircraft manufacturer and analyze the effectiveness of our technologies

\section{Conclusion}

In this article there were analyzed the new technologies for aircraft manufacturer company: Lean Manufacturing and Internet of Things, which can significantly improve the production system.

There were made the following conclusions through this paper:

- Lean Manufacturing can lead to the following results: improve productivity and quality of the production system, decrease the costs and the lead time.

- By using Internet of Things devices and tools, you can achieve the whole collaboration system of suppliers, manufacturers and customers, which also lead to the cost and time decrease.

- Integration of Lean and IoT will lead to the great efficiency of aircraft manufacturing, because all members and workers will be able to get an access to the data any time and control the processes easily and quickly.

- Lean and IoT technologies can be successfully implemented in aviation industry. It can be proved by the successful case study of Boeing aircraft manufacturer company.

- Before realizing its implementation on the real practice, firstly it is needed to understand its work on the simulation model. By analyzing all process improvement simulation methods, it was made a decision to use Discrete Event Simulation. ARENA software, which is based on this method, can give us the necessary output parameters and help to analyze the system after new technologies implementation.

In the simulation model we will base on the following results: WIP, lead time and inventory reduction, because IoT and Lean technologies effect mainly consists of these parameters. 


\section{References}

1. A. Jayaram, 2nd International Conference on Contemporary Computing and Informatics, 89-94 (2016)

2. W. Lian-yue, IEEE Symposium on Robotics and Applications (ISRA), 436-438 (2012)

3. T. Wagner, C. Herrmann, S. Thiede, 50th CIRP Conference on Manufacturing Systems, 125-131 (2017)

4. A. Vyalov, Lean manufacturing, textbook (Komsomolsk-on Amur's Aviation plant of Y.Gagarin, Komsomolsk-on-Amur, 2014)

5. M. Melnikov, K. Tereshenko, Actual problems of aviation and cosmonautics 1, 27-28 (2014)

6. V. Crute, Y. Ward, S. Brown, A. Graves, Technovation 23, 917-928 (2003)

7. I. Alhuraish, C. Robledo, A. Kobi, 6th IESM Conference, Seville (2015)

8. F. Abdulmalek, J. Rajgopal, Production Economics 107, 223-236 (2007)

9. Y. Zhang, F. Tao, Optimization of Manufacturing Systems Using Interent of Things, textbook (2016)

10. A. Roslyakov, S. Vanyashin, A. Grebeshkov, Internet of Things, textbook (Povolzhskiy State University of Telecommunications and Informatics, Samara, 2015)

11. L. Sun, J. Liu, R. Higgs, L. Zhou, IEEE International Conference on Computational Science and Engineering (CSE) and IEEE International Conference on Embedded and Ubiquitous Computing (EUC), 437-442 (2017)

12. T. Aydos, J. Ferreira, IEEE International Conference on Automation Science and Engineering (CASE), 1140-1145 (2016)

13. M. Grace, D. Smith, L. Juhnke, S. Dalton, Boeing Technical Journal, 1-10 (2016)

14. R. Rencher, Internet of Things: Digital Business Transformation (Industrial Internet Consortium, 2015)

15. A. Goienetxea Uriarte, A.H.C. Ng, E. Ruiz Zúñiga, M. Urenda Moris, IEEE International Conference on Industrial Engineering and Engineering Management, 1245-1250 (2017)

16. J. Banks, Handbook of Simulation - Principles, Methodology, Advances, Applications, and Practice (Wiley \& Sons, 1998)

17. E. Ruiz Zúñiga, M. Urenda Moris, A. Syberfeldt, Winter Simulation Conference, 38283839 (2017)

18. F. Lucherini, M. Rapaccini, Journal of Industrial Engineering and Management, 919945 (2017)

19. Q. Liu, H. Yang, 29th Chinese Control and Decision Conference (CCDC), 3390-3395 (2017)

20. P. Solding, P. Gullander, Winter Simulation Conference, 2231-2237 (2009)

21. P. Dahl, H. Eliasson, Master Thesis in Production Engineering (Chalmers University of Technology, Sweden, 2011)

22. I. Basoukos, J. Spangberg, Master Thesis in Production Engineering (Chalmers University of Technology, Sweden, 2015)

23. O. Omogbai, K. Salonitis, 49th CIRP Conference on Manufacturing Systems, 195-200 (2016)

24. R. Detty, J. Yingling, International Journal of Production Research, 429-445 (2000) 
25. M. Adams, P. Companation, H. Czarnecki, B. Schroer, Winter Simulation Conference, 766-773 (1999)

26. A. Uriarte, M. Urenda Moris, A. H.C. Ng, J. Oscarsson, Winter Simulation Conference, 2227-2238 (2015)

27. C.R.A. Hallam, Lean Supply Chain Management Techniques for Complex Aerospace Systems: Using Discrete Event Simulation to Mitigate Programmatic Cost and Schedule Risk (USA, 2010)

28. M. Dotoli, M.P. Fanti, G. Iacobellis, G. Rotunno, 8th IEEE International Conference on Automation Science and Engineering, 668-673 (2012)

29. D. Kisilev, Y. Kisilev, V. Bibikov, Simulation modeling of information systems in the package ARENA (Samara State Aerospace University, Samara, 2014)

30. M. Bahtiyar, Master Thesis in Mechanical Engineering (Middle East Technical University, 2005) 